\title{
Volume Deformation Characteristics of Concrete Mixture during Thermal Curing Process
}

\author{
Y Xiang ${ }^{\mathrm{a}}$, Y Xie, G Long and L Li \\ School of Civil Engineering, Central South University, No 22 South Shaoshan Rd, 410075, Changsha, Hunan, PR \\ China
}

\begin{abstract}
Expansion deformation of concrete mixture during steam curing process was a kind of unrecoverable volume expansion which would definitely affect the performance of concrete component. Because there were a few researches on expansion deformation of concrete mixture during thermal curing process, a new test method composed of constant temperature water bath, eddy current measurement sensor and data processing program was developed to measure the expansion deformation. The volume deformation characteristics of a typical concrete used for preparing track slab of China high-speed railway were investigated. Test results indicated that volume deformation of concrete mixture could be divided into 2 stages. One was rapid expansion at heating stage and another one was slow shrinkage at constant temperature stage. Besides, the addition of combination of flying ash, slag, nano-silica and nano-calcium carbonate was benefit for controlling the eventual expansion deformation during the whole thermal curing process. Study could be an important reference for heightening quality of steamcured concrete.
\end{abstract}

\section{Introduction}

China is now rapidly developing the high-speed railway. In order to improve the turnover rate of mould and accelerate the construction schedule to ensure the project would be completed on time or in advance, many concrete components such as sleeper, track slab and prestressed simply supported box girder are prefabricated by means of high temperature steam curing. Then, these concrete components would be towed to construction sites for assembly and splicing after experiencing above curing process. It is true that steam-cured concrete components could be quickly produced batches; however, through years of monitoring a large number of high-speed rail projects, researchers have found that this kind of concrete exposes a considerable number of problems during the service process [1-5].

Experiments prove that due to a series of physical and chemical reactions during steam curing process happened within concrete mixture, volume expansion, chemical shrinkage, autogenous shrinkage and temperature deformation are produced which always results in causing surface and interior cracks. These initial cracks would begin to deteriorate during the long-term service under alternate cycling of temperature, rainwater, chemistry and train dynamic load conditions. Finally, mechanical and durability performances of concrete components are eventually becoming worsen and the service life is definitely shortened [6-8].

Expansion deformation is the most prominent thermal damage of concrete mixture during steam curing process. This kind of volume deformation is a comprehensive deformation which consists of

\footnotetext{
a Corresponding author : Niesh2013@126.com
} 
minority of expansion of solid phase and chemical shrinkage of hydration and majority of free expansion of liquid phase and vapour phase. Since the restrain effect of mould, internal vapour moves upward drives some cementing component particles to move upward which makes the early concrete skeleton structure grow upward. With continuous hydration of cementing component particles, those products gradually fill up pores and cracks caused by vapour evaporation and the framework of concrete is basically formed, which would finally cause the unrecoverable volume deformation.

Nowadays, because there are a few researches on volume deformation characteristics of concrete mixture during steam curing process, this study has developed a new test method to imitatively measure the deformation. The influences of different cementing components on volume deformation of concrete mixtures during thermal curing process are analyzed and the deformation rule is further explained by testing evaporable water content and compressive strength. Study provides an important reference of controlling volume deformation and heightening quality of steam-cured concrete.

\section{Raw materail and methodology}

\subsection{Raw materials}

Raw materials adopted in this study include cement (C), flying ash (FA), ground granulated blast furnace slag (GGBS), nano-silica (NS), nano-calcium carbonate (NC) particles, coarse and fine aggregates, high-efficient superplasticizer (SP) and water (W). Main technical features of above raw materials are shown as followed: (I) C is P.I 42.5 Portland cement and grades of FA and GGBS are first class and S95, separately. Technical indices of C, FA, GGBS, NS and NC are presented in table 1 and table 2. (II) Fine aggregates are ordinary river sands whose fineness modulus is 2.8. Coarse aggregates are crushed limestone. (III) Water reducing efficiency of SP is $25 \%$ and tap-water is adopted to use as the mixing water.

Table 1. Technical properties of C, FA and GGBS.

\begin{tabular}{lccccccccc}
\hline \multicolumn{1}{c}{ Type } & \multicolumn{8}{c}{ Content (w\% by weight) } & \multicolumn{2}{c}{ Specific area } \\
& $\mathrm{SiO}_{2}$ & $\mathrm{Al}_{2} \mathrm{O}_{3}$ & $\mathrm{FeO}$ & $\mathrm{CaO}$ & $\mathrm{MgO}$ & $\mathrm{SO}_{2}$ & $\mathrm{Na}_{2} \mathrm{O}_{\mathrm{eq}}$ & $\mathrm{I} . \mathrm{L}$ & $\left(\mathrm{m}^{2} \cdot \mathrm{g}^{-1}\right)$ \\
\hline $\mathbf{C}$ & 24.6 & 7.3 & 4 & 59.7 & 3.8 & 2.5 & 0.6 & 2.5 & 367 \\
FA & 52.3 & 26.3 & 9.7 & 3.7 & 1.2 & 0.2 & 1.8 & 5.7 & 450 \\
GGBS & 26.1 & 13.8 & 14.1 & 33.6 & 8.1 & 1.75 & 0.45 & 2.1 & 420 \\
\hline
\end{tabular}

Table 2. Technical properties of nano particles.

\begin{tabular}{lcccc}
\hline Type & Specific area $\left(\mathrm{m}^{2} \cdot \mathrm{g}^{-1}\right)$ & Diameter $(\mathrm{nm})$ & \multicolumn{2}{c}{ Content $(\mathrm{w} \%$ by weight) } \\
& & & $\mathrm{SiO}_{2}$ & $\mathrm{CaCO}_{3}$ \\
\hline NS & $640 \pm 50$ & $10 \pm 5$ & $>99.9$ & 1 \\
NC & $45 \pm 5$ & $35 \pm 5$ & 1 & $>96.5$ \\
\hline
\end{tabular}

\subsection{Test mix proportions}

Considering effects of mineral admixtures and nano particles on volume deformation characteristics of concrete mixture during thermal curing process, 6 test mix proportions of concrete specimens are designed and presented in table 3. 
Table 3. Mix proportions of concrete specimens $(\mathrm{Kg} / \mathrm{m})$.

\begin{tabular}{|c|c|c|c|c|c|c|c|c|c|c|}
\hline \multirow[t]{2}{*}{ Type } & \multirow[t]{2}{*}{$\mathrm{C}$} & \multirow[t]{2}{*}{ FA } & \multirow[t]{2}{*}{ GGBS } & \multirow[t]{2}{*}{ NS } & \multirow[t]{2}{*}{$\mathrm{NC}$} & \multirow[t]{2}{*}{ Sand } & \multicolumn{2}{|c|}{ Stone } & \multirow[t]{2}{*}{ SP } & \multirow[t]{2}{*}{ W } \\
\hline & & & & & & & $5-10 \mathrm{~mm}$ & $10-20 \mathrm{~mm}$ & & \\
\hline CO & 450 & 0 & 0 & 0 & 0 & 660 & 484 & 726 & 4.5 & 135 \\
\hline M1 & 315 & 135 & 0 & 0 & 0 & 660 & 484 & 726 & 4.5 & 135 \\
\hline M2 & 315 & 0 & 135 & 0 & 0 & 660 & 484 & 726 & 4.5 & 135 \\
\hline M3 & 315 & 90 & 45 & 0 & 0 & 660 & 484 & 726 & 4.5 & 135 \\
\hline N1 & 313.425 & 90 & 45 & 0 & 1.575 & 660 & 484 & 726 & 4.95 & 135 \\
\hline N2 & 313.425 & 90 & 45 & 1.575 & 0 & 660 & 484 & 726 & 4.95 & 135 \\
\hline
\end{tabular}

In above mix proportions, $30 \% \mathrm{C}$ is replaced by FA or GGBS or both of them and another $0.5 \% \mathrm{C}$ is further replaced by nano particles.

\subsection{Test programs}

\subsubsection{Expansion deformation.}

Expansion deformation test mainly contains following 3 procedures.

(I) Preparation for concrete specimens: $100 \mathrm{~mm} \times 100 \mathrm{~mm} \times 515 \mathrm{~mm}$ size stainless steel moulds are used to form concrete specimens and there are 3 specimens in each mix proportion. A thin layer of hydraulic oil should be applied to bottom and inner walls of mould first. Beside, in order to get expansion deformation of concrete mixture under unrestrained actions, two $3 \mathrm{~mm}$ thick cardboard shells are placed along the length direction of mould, two $10 \mathrm{~mm}$ thick polytetrafluoroethylene boards are placed at both ends of mould and finally a layer of polytetrafluoroethylene thin film is placed inside the bottom and inner walls of mould. When reflection targets have been fixed, concrete mixture is poured layer by layer and vibrated densely. It is noteworthy that distance between 2 reflection targets is no less than $400 \mathrm{~mm}$. When vibration has been finished, a layer of plastic thin film should be laid on top of specimen to prevent dry shrinkage and put specimen into test room for $3 \mathrm{~h}$ of static setting.

(II) Calibration of sensors: both cardboard shells and polytetrafluoroethylene boards should be removed first and the plastic thin film should continuously cover specimen's surface. Sensors could be connected with testing system when they have been installed and the distance between sensor and reflection target should be controlled at $1.20 \pm 0.05 \mathrm{~mm}$. Experimental schematic diagram and testing principle are displayed in figure 1 and equation (1).

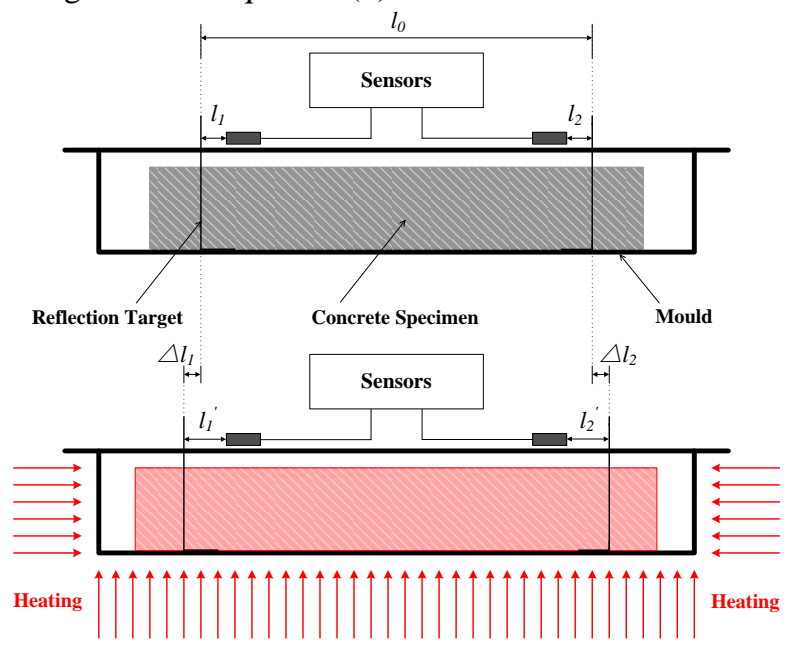


Figure 1. Experimental schematic diagram.

Calculation of volumetric expansion rate $a$ :

$$
\alpha=\frac{\left(l_{1}^{\prime}-l_{1}\right)+\left(l_{2}^{\prime}-l_{2}\right)}{l_{0}} \times 10^{6}
$$

(III) Test procedures: turning on water bath at the beginning to raise test temperature from $20^{\circ} \mathrm{C}$ to $60 \mathrm{C}$ in $2 \mathrm{~h}$ and then to keep the bath temperature at $60 \mathrm{C}$ for $8 \mathrm{~h}$. During the whole thermal curing process, the data are recorded automatically once a minute by testing device and the final result is the average value of 3 specimens. Thermal curing scheme and testing device are shown in figure 2 and figure 3 , respectively.

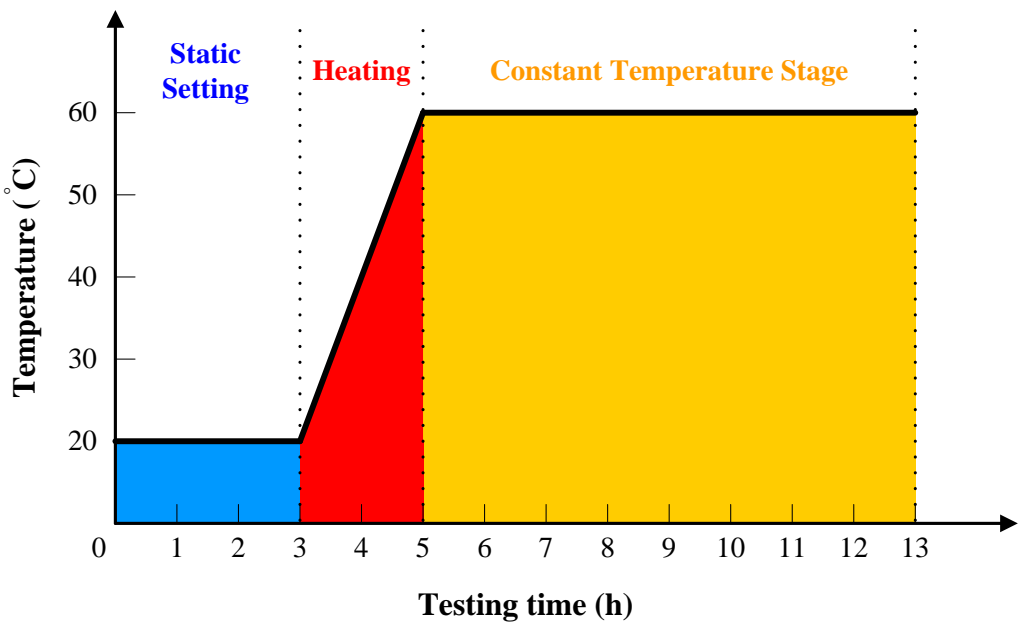

Figure 2. Thermal curing scheme.

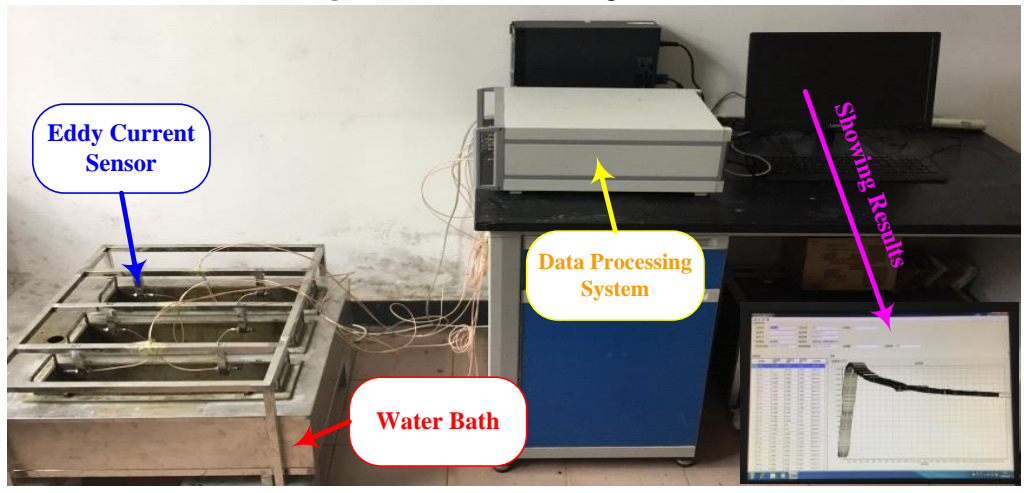

Figure 3. Experimental device.

\subsubsection{Compressive strength.}

Surplus concrete mixture of 2.3 .1 section's test is adopted to fabricate $6100 \mathrm{~mm} \times 100 \mathrm{~mm} \times 100 \mathrm{~mm}$ size concrete cubic specimens in 2 detachable steel moulds. After the same $3 \mathrm{~h}$ of static setting in the same test room, removing steel moulds first and compressive strengths of cubic specimens should be measured immediately. Final results would be obtained by calculating tests' average.

\subsubsection{Evaporable water content.}


Broken specimen of 2.3.2 section's would be further crushed into smaller pieces and then be put into a stainless steel basin whose weight is $m_{0}$ to weigh the total mass $m_{l}$. Put this basin with crushed concrete specimen pieces into an oven at $103 \pm 5^{\circ} \mathrm{C}$ for drying. Duing above drying process, the total mass of basin and pieces should be continuously weighted until the total mass does not change anymore and then record the last weight $m_{2}$. The evaporable water content could be calculated by following equation (2).

$$
w \%=\frac{m_{1}-m_{2}-m_{0}}{m_{2}-m_{0}} \times 100 \%
$$

\section{Experimental result and dicussion}

\subsection{Volume deformation characteristics}

It is assumed that thermal expansion coefficient of concrete mixture in the non-hardening stage is $12 \mu / \mathrm{C}$ while $8 \mu{ }^{\circ} \mathrm{C}$ in hardening stage. During thermal curing process, concrete mixture basically takes $1.5 \mathrm{~h}$ to achieve complete hardening state. Thus, when heating stage is over, temperature strain of concrete is $440 \mu$ and this value would be kept unchanged in constant temperature stage. The true volume deformation curve of concrete is the result of test curve deducts temperature strain.

It can be seen from all volume deformation tests of concrete mixtures that volume deformation characteristics mainly contain 2 stages. On the one hand, due to insufficient hardening of concrete mixture during the temperature-rising stage, huge expansion deformation caused by water vapor's expansion makes the deformation curve rise fast. On the other hand, with the help of gradual hardening of concrete and steady temperature, expansion deformation has basically stopped. Because of continuing hydration of cementing components, a shrinkage phenomenon of concrete has came out which results in declining the deformation curve in this constant temperature stage.

Concrete mixtures incorporating different cementing components have little differences of thermal expansion ratios in temperature-rising stage; however, their thermal expansion deformation peaks are various. Effects of mineral admixtures and nano particles on volume deformation characteristics have been discussed.

\subsubsection{Inhibition effects of mineral admixtures.}

As is shown in figure 4, despite different thermal expansion peaks, the deformations of concrete specimens incorporating different mineral admixtures have no obvious differences in heating stage; however, when tests reach constant temperature stage, their deformation values of specimens become clearly different. Besides, shrinkage deformations are various from each specimen.

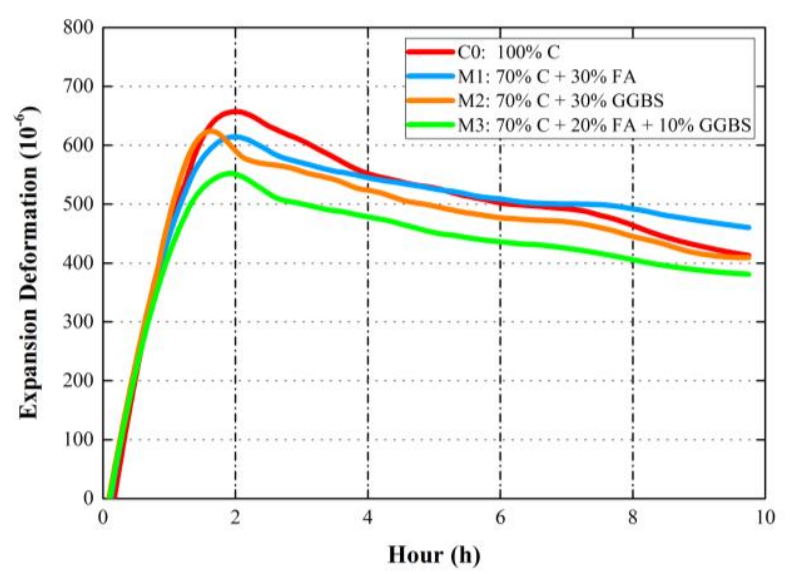


Figure 4. Effects of mineral admixtures on controlling volume deformation.

Figure 4 has presented following changes: $\mathrm{C} 0$ group has the biggest expansion peak $650 \mu$ but it reduces $250 \mu$ in the end. M1 and M2 groups own similar maximum expansion deformations near $615 \mu$ however M2 group could achieve that value faster. Shrinkage trend slows down when M1 group enters constant temperature stage and final expansion value is higher than $\mathrm{C} 0$ group whereas shrinkage of M2 group continuously enlarges and final expansion is slightly lower than C0 group. M3 group not only has the smallest expansion peak $550 \mu$ but also owns the lowest final expansion value $380 \mu$. Above test results imply FA and GGBS have a great influence on controlling volume deformation of concrete mixture. Concrete specimen incorporating single GGBS could fast arrive at the maximum expansion peak, but concrete specimens incorporating single FA or mingle FA-GGBS could reach that peaks until heating stage is over. During the constant temperature stage, expansion deformations of concrete specimens gradually change into obvious shrinkage deformations. C0 group has the largest reduction of shrinkage deformation and followed by M2 group, which means although GGBS has replaced 30\% C it still promotes hydration of cement. However, trends and values of shrinkage deformations of concrete specimens incorporating single FA or mingle FA-GGBS slightly decline. Test results present GGBS plays an important role in deformation changes of concrete at temperature-rising and constant temperature stages.

Causes of above experimental phenomenon are related to greater activity of GGBS and density of initial pore structure of concrete mixture. Though activity of FA is small and its hydration process is slow, the addition of combination of FA and GGBS still forms the "superimposed compound effect" to enhance the initial structure [9-10]. Thus, M3 group heightens compactness and initial pore structure and promotes early hydration to generate higher expansion deformation resistance force of concrete mixture which resulted in controlling the development of initial thermal expansion during temperature-rising stage and restraining shrinkage deformation in constant temperature stage.

\subsubsection{Reinforcement effects of nano particles.}

$\mathrm{N} 1$ and $\mathrm{N} 2$ groups' mix proportions are based on M3 group but there are $0.5 \% \mathrm{NC}$ and $0.5 \% \mathrm{NS}$ have further replaced of $\mathrm{C}$, respectively, to carry out expansion deformation experiments. Test results are displayed in figure 5 and results indicate that nano particles have significant effects on further restraining the thermal expansion deformation peaks and increasing shrinkage deformations.

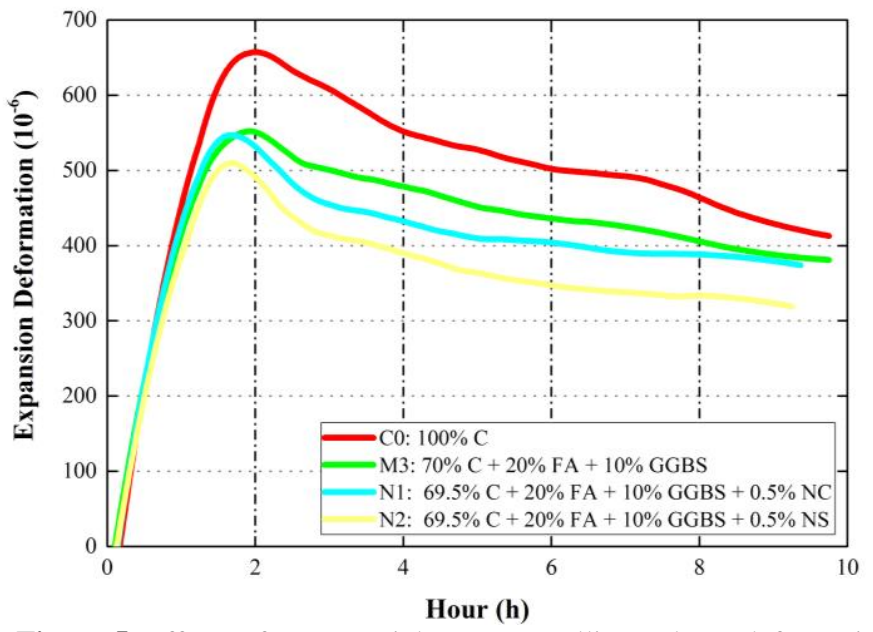

Figure 5. Effects of nano particles on controlling volume deformation.

Figure 5 has shown following changes: when nano particles are blended in concrete mixtures, expansion deformation peaks of $\mathrm{N} 1$ and N2 groups decrease in temperature-rising stage, besides, N2 group drops more obviously. Meanwhile, shrinkage deformation of N2 group is more severe while that of N1 group is relatively gentle. When tests are about to end, final expansion value of N1 group 
nears M3 group but that of N2 group is close to $320 \mu$. Experimental results show the addition of small amount of nano particles help to reduce thermal expansion peaks and promote shrinkage deformations of concrete mixtures during thermal curing process.

Explanations for these experimental results may be illustrated as followed. Nano particles, due to their nano-scale's particle size and huge specific area, efficiently reduce free water content and exert excellent physical filling effect. The initial pore structure of concrete mixture has been improved which provides a stronger resistance force to further restrain the expansion deformation during heating stage. On the other hand, nano particles have not only higher activity but also pozzolanic effect, which promotes cement hydration, changes product phase and fills up more pores. Since hardened cement and early framework of concrete mixture have been formed, the ability to resist thermal expansion deformation has been finally enhanced [11-12]. It is noteworthy that when experiments enter constant temperature stage, shrinkage deformation of $\mathrm{N} 1$ group declines fast first and then gradually smoothly because the ability of NC to continuously promote hydration is limited.

\subsection{Relationship between initial structural state and deformation}

Initial structural state is vital for concrete mixture's thermal deformation characteristics during whole thermal curing process. Initial structural indices are mainly consist of evaporable water content, pore ratio, setting time and compressive strength. In order to expediently carry out experiments, evaporable water content and compressive strength are investigated because these specimens could be synchronously prepared when fabricating volume deformation test specimens. Test results are listed in table 4.

Table 4. Initial structural indices and expansion peaks.

\begin{tabular}{lccc}
\hline Type & $\begin{array}{c}\text { Evaporable Water Content } \\
\text { (w\% by weight) }\end{array}$ & $\begin{array}{c}\text { Compressive Strength } \\
\text { (MPa) }\end{array}$ & $\begin{array}{c}\text { Thermal Expansion Peak } \\
(\mu)\end{array}$ \\
\hline C0 & 28.3 & 2.44 & 657.0473 \\
M1 & 28 & 2.65 & 614.3168 \\
M2 & 27.1 & 2.87 & 623.8592 \\
M3 & 25.8 & 3.11 & 551.9716 \\
N1 & 23.2 & 3.83 & 546.737 \\
N2 & 20.5 & 4.28 & 509.5949 \\
\hline
\end{tabular}

It can be seen from table 4, concrete mixtures incorporating different cementing components have distinct compressive strengths and evaporable water contents. C0 group owns the highest evaporable water content and lowest compressive strength. When FA and GGBS have replaced cement separately, changing trends of initial indices of M1 and M2 groups are similar. Their evaporable water contents decline and compressive strengths rise. However, GGBS's catalytic effect on early hydration of cement and the place where nucleation happens provided by it also helps to continuously produce more hydration, which results in consuming more free water and heightening bigger early strength of concrete mixture. Because of superimposed compound effect of FA-GGBS, initial pore structure of concrete mixture has been improved and early hydration of cement has been promoted, which further reduces the water content and raise the strength of M3 group to a certain extent [13]. When nano particles are added into concrete, evaporable water contents of $\mathrm{N} 1$ and $\mathrm{N} 2$ groups significantly decline. Above experimental phenomenon is related to surface properties of NS and NC. These nano particles absorb and consume most free water within concrete mixtures, besides, NS owns a much higher specific area than NC, therefore N2 group has the obviously lowest evaporable water content. With the help of nano particles, superimposed compound effect has been further enhanced and some nanoscale and micro pores would be filled. Then, hydration products of cement and NS would fill up these pores again, which makes concrete specimens become more compact and have a higher compressive strength at the same time.

Besides, according to the data given in table 4, relationships between initial structural indices and thermal expansion peaks have been mathematically fitted and results are displayed in figure 6 . 
Figure 6 implies that both evaporable water content and compressive strength are exponentially related to thermal expansion peaks. The greater water content, the greater thermal expansion. Besides, the greater initial strength, the smaller thermal expansion. It is obvious that when concrete incorporating mineral admixtures, a reasonable mixing proportion of mineral admixtures is conducive to the generation of superimposed component effect. On this basis, adding nano particles into concrete mixture can further fill internal pores and strengthen a more compact initial structure. On the other hand, with continuing cement hydration and joint effects of mineral admixtures and nano particles, free water is constantly consumed. At the same time, these materials can absorb most of free water which helps to decrease the content of free water in setting stage and evaporable water in curing stage.
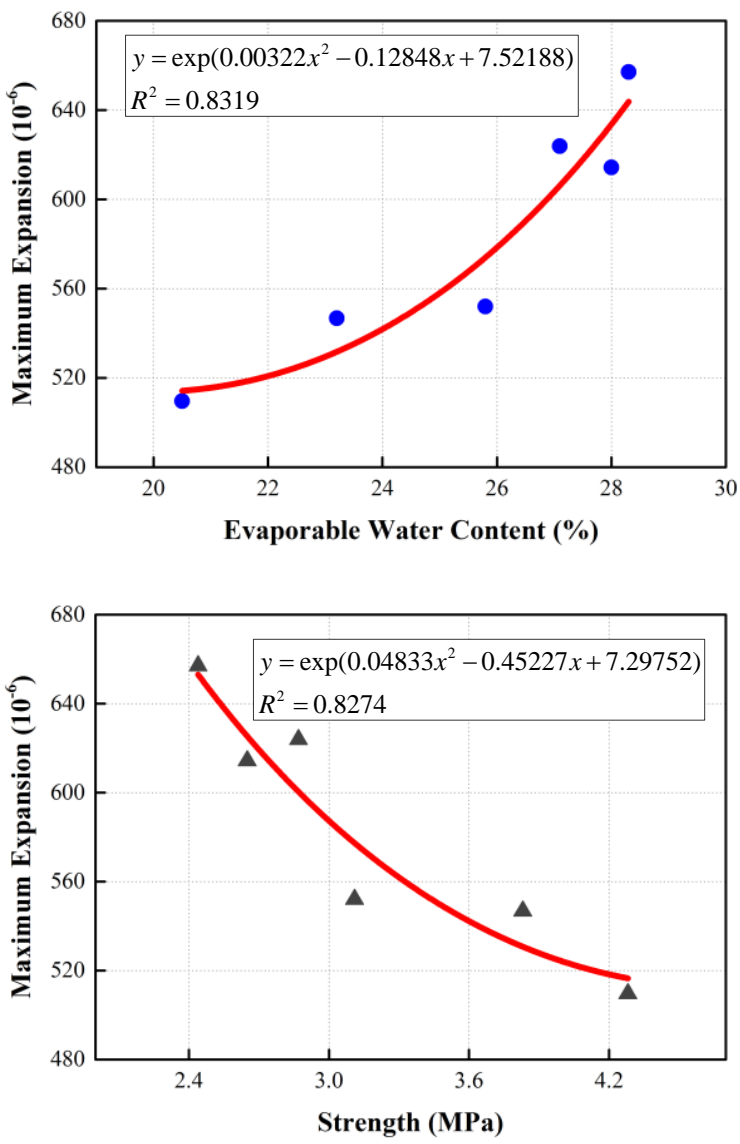

Figure 6. Relationship between initial indices and thermal deformation.

Considering above two aspects, because a denser initial structure has formed and hydration products have been rapidly generated and then fill most nano-scale's and mirco pores, concrete owns a certain strength to resist thermal expansion during thermal curing process. At the same time, consumption of free water greatly reduces vapor evaporation movement which results in further restraining early volume expansion. Therefore, preparing concrete incorporating mineral admixtures and a small amount of nano particles could reduce thermal expansion deformation during the whole thermal curing process.

\section{Conclusion}

Volume deformation characteristics of concrete mixture could be divided into 2 stages: thermal expansion rising rapidly in temperature-rising stage and shrinkage deformation happens slowly in 
constant temperature stage. During the whole experimental process, the final feature of concrete specimen is dominated by expansion deformation.

Compared with FA, GGBS has better effects on restraining early thermal expansion and increasing shrinkage. Concrete mixture incorporating 20\% FA and 10\% GGBS owns small thermal expansion deformation peak and gentle shrinkage. After adding nano particles, the superimposed compound effect has been further enhanced. With the joint effects of mineral admixtures and nano particles, the more free water is absorbed and consumed, the less expansion caused by evaporation would happen. Besides, due to the stronger initial anti-deformation ability and skeleton strength, thermal expansion deformation would be eventually restrained. The recommended dosages of FA, GGBS and NS for replacing cement are $20 \%, 10 \%$ and $0.5 \%$, separately.

\section{Acknowledgments}

This study is financially supported by the National Natural Science Foundation of China (Grant No U1534207, 11790283 and 51678568). Authors thank Mr. Q Y Xiao for his great help to accomplish experimental tasks. Meanwhile, authors also appreciate those who are reviewing this paper for your kind concern about construction technology of high-speed railway in China.

\section{References}

1. Ma K, Long G and Xie Y 2017 Case Studies in Construction Materials 663

2. Long G, Yang J and Xie Y 2017 Constr. Build. Mater. 136456

3. Ma K, Xie Y and Long G 2014 Sci. China Technol. Sci. 571909

4. Long G, Wang M, Xie Y and Ma K 2014 Sci. China Technol. Sci. 571902

5. Pater H, Bland C H and Poole A B 1995 Cem. Concr. Res. 25485

6. Liu B, Luo G and Xie Y 2018 Constr. Build. Mater. 167359

7. Zou C, Long G, Ma C and Xie Y 2018 Constr. Build. Mater. 188424

8. Lothenbach B, Winnefeld F, Alder C, Wieland E and Lunk P 2007 Cem. Concr. Res. 37483

9. Wang Q, Li M and Zhang B 2014 J. Therm. Anal. Calorim. 1181505

10. He Z, Long G and Xie Y 2012 J. Cent. South Univ. 191155

11. Long G, Li Y, Ma C, Xie Y and Shi Ye 2018 Thermochim. Acta 664108

12. Mei J, Ma B, Tan H, Li H, Liu X, Jiang W, Zhang T and Guo Y 2018 Constr. Build. Mater. 171 83

13. Ho D W S, Chua C W and Tam C T 2003 Cem. Concr. Res. 33595 